\title{
Data Visualization in Scandinavian Newsrooms
}

\author{
Emerging Trends in Journalistic Visualization Practices
}

\author{
Martin Engebretsen, Helen Kennedy \& Wibke Weber
}

\begin{abstract}
The visualization of numeric data is becoming an important element in journalism. In this article, we present an interview study investigating data visualization practices in Scandinavian newsrooms. Editorial leaders, data journalists, developers and graphic designers in 10 major news organizations in Norway, Sweden and Denmark provide information for the study on a range of issues concerning visualization practices and experiences. The emergence of multi-skilled specialist groups as well as innovation in technology and the 'mobile first mantra' are identified as important factors in the fast-developing practices of journalistic data visualization. Elements of tension and negotiation are revealed for issues concerning the role and effect of complex exploratory data visualizations and concerning the role of ordinary journalists in the production of charts and graphs.
\end{abstract}

Keywords: data visualization, visualization practices, newsroom studies, journalism, datafication

\section{Introduction}

Data visualization plays an increasingly important role in journalism, as many scholars have noted (e.g., Rinsdorf \& Boers 2016; Appelgren 2017; Loosen et al. 2017), as data visualizations affect both journalistic content and interactional patterns of news discourse (Engebretsen 2017). ${ }^{1}$ These developments parallel the general trend of 'datafication' in society, that is, quantification of aspects of life previously experienced in qualitative, non-numeric forms, which are then tabulated, analyzed and visualized (see, e.g., Mayer-Schoenberger \& Cukier 2013; van Dijck 2014; Couldry 2016). This cultural trend includes an increased accessibility of public data and easier ways of mediating them through a growing array of visualization tools. Together, these factors contribute to an increased presence of data in newsrooms and to a growing focus on data visualization (DV) as an integrated element in journalistic genres (e.g., Weber \& Rall 2012; Gynnild 2013).

Engebretsen, Martin, Kennedy, Helen \& Weber, Wibke (2018). Data Visualization in Scandinavian Newsrooms. Emerging Trends in Journalistic Visualization Practices in Nordicom Review 39 (2018) 2, pp. 3-18. doi:10.2478/nor-2018-0007. 
Journalists and editors are thus confronted with evolving production practices, involving complex textual formats that combine words and numbers with graphic modes and new software tools for collecting, analyzing and visualizing data (cf. Gynnild 2013; Kennedy et al. 2016; Engebretsen \& Weber 2017; Weber 2017). At the same time, new interfaces for displaying information have come to dominate: smartphone screens. As seen in this study, the 'mobile first' mantra has become an organizing principle in many major newsrooms.

In this article, we present results from a qualitative interview study that focused on data visualization practices in 10 Scandinavian newsrooms. The study is part of an ongoing wider project, covering visualization practices in 26 European newsrooms. ${ }^{2}$ The aim is to reveal emerging trends and critical factors in current visualization practices. Knowledge of such practices contributes to our understanding of journalistic genre developments and the role that DV plays in these developments. Results of the study also support practitioners in their evaluation of their own visualization practices, allowing them to compare their own practices to larger trends.

Our analysis is framed by a focus on genre. In neo-rhetorical genre theory, genres are closely related to social practices (cf. Miller 1984). Genre conventions regulate textual forms and contents that are regarded as acceptable - or even creative - by both producers and consumers of utterances used in particular recurring social contexts (Miller 1984). This is also the case for journalistic genre norms or what is regarded as 'the gold standard' of news stories, investigative reports, weekend features, etc. These standards are recognized by certain stable elements, shaped through history by the basic social functions that textual outputs serve. However, at the same time, they are shifting, due to changing technological and semiotic affordances, parallel changes in consumption patterns and broader developments relating to roles of journalism in society (Engebretsen 2008; Lüders et al. 2010). Importantly for this article, genre change also relates to shifting processes and preferences of producers, as genre conventions always form through social and textual practices (Miller 1984).

This study contributes to existing knowledge about the role that DV plays in current journalism by investigating trends and drivers in newsroom practices. While text analysis answers the 'what' of genre development, production studies contribute to answer the 'how' and 'why'. This article, therefore, asks:

(1) What characterizes the processes of data visualization production in Scandinavian newsrooms?

(2) What reflections and experiences inform these processes?

(3) What are the implications for genre development?

While many newsroom studies have investigated the broader picture of data-driven journalism in recent years, very few have focused on visualization practices, per se, nor have they explored the role of DV from the perspective of genre development. ${ }^{3}$

By 'data visualization', we mean a visual representation of (most often numeric) data, created to amplify the cognitive processing and social application of data represented (cf. Borgo et al. 2013; Cairo 2013). Data visualization is distinct from 'information graphics', as Kennedy and Allen write, in that the former 'has data at its heart' (2016: 309 ) and will often use abstract, geometrical forms to represent numeric values and 
relations. In contrast, an infographic explains phenomena graphically but may contain either no data or data alongside other illustrations, like photographs. Data visualization is not equivalent to 'data journalism' or 'data-driven journalism', but such forms of journalism often include data visualization as a tool for storytelling (Loosen et al. 2017).

Data visualizations come in a wide range of graphical forms. To illustrate the object of study, Figure 1 shows just one of many examples: an interactive data visualization concerning train delays, published on the news site of the major Norwegian tabloid Verdens Gang. Based on data collected from Norwegian railway authorities, the visualization invites readers to explore when and where train delays took place during 2016, with the help of coloured circles, a zoomable map and an interactive timeline.

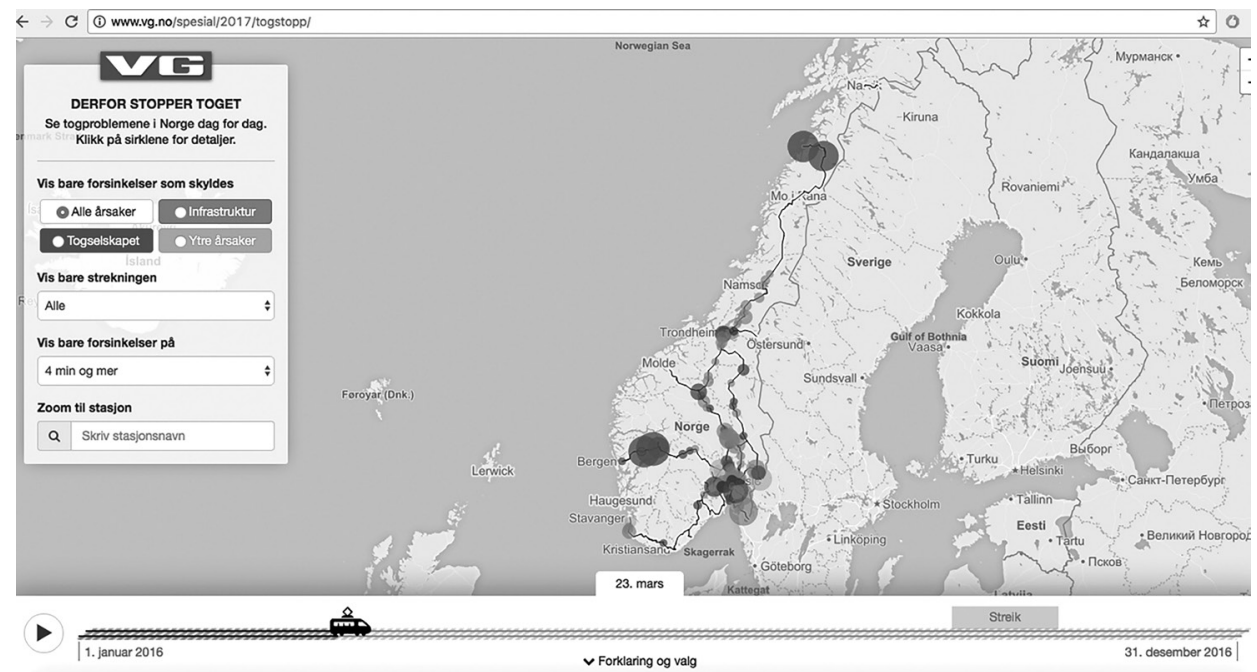

Figure 1. Derfor stopper toget [That's why the train is delayed]. Data visualization by Verdens Gang.

Comments: The visualization, showing all instances of delay at Norwegian railway stations during 2016, was published in the online version of Verdens Gang. With a click of the mouse, the user can choose only to see delays on a certain line or delays due to a specific reason (Retrieved from http://www.vg.no/spesial/2017/togstopp/, 15 January 2018).

\section{Related work on data visualization}

In the context of a growing focus on application of DV in the public sphere, a number of relevant contributions address the perspective of DV practitioners, offered by statisticians and information designers. Such contributions address key practitioner questions, such as how to design numbers in a clear and effective way (Few 2004; Yau 2011; Mollerup 2015), how to improve data displays (Kosslyn 2006; Malamed 2009; Meirelles 2013) and how to tell stories with data (Cairo 2013, 2016; Nussbaumer Knaflic 2015).

Alongside the academic and professional conversation concerning the usability and effectiveness of data visualizations, another strand of literature discussing data visualization as a socially situated, discursive and rhetorical resource is emerging. Building on semiotic work by pioneers like Bertin (2011 [1967]) and Kress and van Leeuwen (2006 
[1996]), this strand of literature investigates the forming of visual and social conventions within data visualization, the regulation of forms and applications of data visualizations in various social arenas, and issues of power and participation (Hullman \& Diakopoulos 2011; Kennedy et al. 2016; Engebretsen \& Weber 2017).

Research on data journalism as a set of evolving journalistic practices and products has also gained momentum in recent years. Recent studies point out that data have become an important content element in news stories and DV an important formal element, often produced by specialized, cross-disciplinary newsroom teams (Hannaford 2015; Ausserhofer et al. 2017). Rinsdorf and Boers (2016) state that application of big data sets and new practices of data journalism are part of a general change in journalism from a focus on news and disclosure to a focus on background information and explanation of current trends. It also fits, they say, a trend towards user integration and a turn from product to process. ${ }^{4}$ Product-oriented studies have revealed that everyday data-driven news stories most often include static DVs in the forms of bar charts, line graphs and maps (Stalph 2017), while award-winning projects often offer interactive features and sometimes include elements of animation (Loosen et al. 2017; Young et al. 2017). In their study of best practices in a Canadian context, Young et al. (2017) conclude that there is a lack of clear standards as to what is considered excellence in the field of data journalism.

The issue of interactivity is central in debates about the development of digital journalism and data visualization in particular, as Young et al. (2017) point out. McMillan (2006) defines interactivity as the facilitation of active-user participation, with respect to content displayed on the screen (such as navigation and filtering), to other human participants (responding, sharing) or to the system of computer-mediated representation (switching between display options). Interactivity is thus seen as a basic and unique aspect of online communication and is often presented as a core characteristic of digital journalism (Boczkowski 2004; Engebretsen 2006). Studies of journalistic practice indicate, however, that online interactivity represents a field of myth and tension, the primary tension being between an idealized image of an active and motivated explorer of a visualized dataset, on one hand, and conventionalized practice of quick and scrolling news reading, on the other (Domingo 2008; Burmester et al. 2010; Young et al. 2017). A high level of interactivity can also come into conflict with the traditional privilege of journalists as storytellers. A recent study of 31 data journalistic projects submitted to the Nordic Data Journalism Awards in 2013, 2015 and 2016 concludes that interactive elements often offer merely an illusion of interactivity, as most choices already are made or predefined by journalists (Appelgren 2017).

In the Scandinavian context, little research has been done with respect to practices and conceptualizations connected to data visualization in newsrooms. In 2014, Karlsen and Stavelin published an interview study that took place in six major newsrooms in Norway, reporting that the emerging practices of computational journalism were guided by traditional aims and methods of investigative journalistic production, although new tools were applied. The 11 informants in this study expressed skepticism towards exploratory data visualizations, focusing rather on design elements embedded in linear, journalist-driven forms of news structure.

From a similar study conducted in seven Swedish newsrooms, Appelgren and Nygren (2014) concluded that data journalism at the time was in a very early stage, that the 
development of new journalistic methods and genre elements was challenged by a lack of time and skills, and that the dominating form of DV was maps.

As this review indicates, although the field of data journalism research is growing, there is a lack of studies investigating in detail the practices of data visualization. This lacuna is particularly evident in studies focusing on Scandinavian newsroom practices.

\section{Methodology}

This article is based on qualitative interviews with staff members in Scandinavian newsrooms; 30 informants from 10 newsrooms in Norway, Sweden and Denmark were interviewed in 21 interviews. The interviewees are editorial leaders, leaders of specialist teams working with data visualizations and other forms of innovative storytelling (called 'visual leaders' hereafter), graphic designers, data developers and (data) journalists. All are involved in the planning and execution of data visualization in their respective news organizations. The selection of news organizations was based on user statistics, as the study aimed to investigate visual practices in mainstream, online news media with large audiences. To achieve a wide range of newsroom types within this frame, the selected organizations include national broadcasters, national broadsheet and tabloid newspapers and one regional newspaper.

All semi-structured interviews were conducted face-to-face in respective newsroom localities, normally within one hour. Interviews were recorded as audio files and, afterwards, transcribed and anonymized. The data were coded and analyzed with help from software for qualitative research, following a content-analysis approach aimed at detecting patterns and trends in the material (cf. Krippendorf 1980).

The aim of the analysis was not to typologize the informants, grouping them into 'types' or 'profiles', but rather to detect patterns and trends in a rapidly evolving field of journalistic practice. Likewise, different professional functions, e.g., graphic designers vs. editorial leaders, have been kept apart in the analysis only when such a separation has proven interesting, due to either the topic in question or the answers given.

The material does not call for a systematic separation between the three Scandinavian countries. There are no indications in the interview data that patterns of visual practices vary significantly across Norway, Sweden and Denmark. This observation is in line with Ahva et al. (2017), who claim that Nordic journalists share the same role perception as well as the political and economic structures framing their work.

\section{Results}

In this section, we elaborate on current trends and critical factors in Scandinavian DV practices, with reference to the following issues: (1) Recruitment and prioritization: What characterizes the building of competences and capacity in the field of DV production? (2) Workflow and routines: Who produces DVs, and what characterizes the processes of production? (3) Motivations and intentions: What roles are DVs assumed to play in journalistic discourses, and what are their intended effects? (4) Platforms and tools: What hardware platforms and software tools are predominant, and what roles do they play in resulting DV formats? (5) Preferred forms of DV: What types of DVs are preferred in newsrooms? (6) Relations to the readers: What do the DV producers know 
about their readers' capabilities, habits and preferences concerning DV on news sites? ${ }^{5}$

(7) Challenges and elements of tension: Are there specific aspects of DV production that cause difficulties or discussions?

\section{Recruitment and prioritization}

The interviews indicate that most major Scandinavian news organizations are gearing up for a stronger integration of data visualization (DV) in their news production. Five of the six editorial leaders interviewed commented directly on this issue, and they all confirmed that people with DV-related skills, such as data handling, visual storytelling and programming, are prioritized when recruiting for the newsroom. For example, in the newsroom of a national broadcaster, the group called 'digital storytelling' grew from three to 14 members between 2013 and 2016. This situation was confirmed by most interviewed visual leaders. One of them put it this way:

Yes, our group is a beloved child, you might say. And all three of us were actually employed while 25 others in the organization had to leave, due to downscaling. So, it was a quite difficult process, but still met with understanding. They understood that if we are to move on, we really need these skills (Visual leader, national broadsheet).

Prioritization of data and visualization skills in recruitment is closely connected to assumptions about rapid future developments in the application of DV in journalism. One editorial leader said:

I think we're going to visualize everything. Everything from what size of shoes people use in different countries to tax percentages to refugee flows, climate problems, housing prices, the level of education between urban districts and regions and continents. Everything is going to be datafied and visualized. I think it's cool (Editorial leader, national broadcaster).

\section{Workflow and routines}

All of the organizations examined, except the smallest one, have a group of expert staff members dedicated to working with data visualizations and other sorts of digital and visual storytelling. The size of the expert group varies from three to 14 persons in the visited organizations. In the groups, different sorts of skills and expertise are combined: expertise in graphic design, front-end web design (also called user experience design), programming and data mining/scraping. None of the groups in the study includes specialists within the mathematical discipline of statistics. Many informants reported, however, that they have developed enough statistical skills to avoid basic mistakes when visualizing statistical material. In all the organizations, it was also claimed that some individual journalists are capable of making simple data visualizations by themselves, without assistance from the specialist group.

These teams, with complementing DV-related competencies, represent a novelty in many newsrooms, and the position of the group in the organization structure varies. In some news houses, the 'visual group' works as a more-or-less independent unit or in close connection with one or more data journalists, creating DVs, infographics and data 
journalism products on their own initiative. However, they equally often produce DV as directed by other groups in the newsroom, or they work as equal partners in joint projects.

\section{Motivations and intentions}

The discursive intentions motivating the application of DV have a strong impact on the development of genres in which DV plays a role, because, as Miller (1984) undelines, the textual forms are always ruled by their social functions. Literature on data visualization often points towards two fundamental (and fundamentally different) functions of DVs. They can either be exploratory, inviting the user to explore one or more datasets more or less freely, or they can be explanatory/illustrative/narrative (the preferred adjective varies), intended to enable the reader to 'see' and understand a specific point or pattern expressed through the visualization (Kirk 2016).

However, this study indicates a wider and more complex set of discursive aims motivating the use of data visualizations in news reporting. Almost all informants point to the basic function of making complex matters more clear and understandable. But besides clarification, the study indicates that data visualizations work, in the context of online news reporting, as a discursive resource with multiple functions. A central function is to emphasize a specific journalistic point/angle.

If you use a DV as a central element in a news story, that DV also has to carry the angle of the story (Data journalist, national broadcaster).

Another function often mentioned by informants is to add empirical evidence to claims made textually in the news story.

I believe that this is the core of our mission, to try to mediate what is correct and true. To find the facts. And facts are often represented by numbers. How many inhabitants are there in our city? That number is a fact, and it does not lie (Editorial leader, regional news house).

A third function is to let the user explore an interactive dataset, often with the possibility of filtering out data that are personally relevant.

We sometimes have a large data set underlying our news stories, and sometimes we give them an interactive interface for the reader to explore by herself. That creates a modern form of 'You-journalism', as it gives you the opportunity to check out your own neighbourhood or something similar (Data journalist, national broadcaster).

A fourth function has to do with aesthetic attraction and the stimulation of interest to which it may lead.

We need to make people feel that it is worth the time to look at the story. And this is partly a generation issue. (..) You have a much better chance to attract the younger readers if you present them with an image and some kind of dynamics. Maybe it is more aesthetical than it is actually pedagogical, but it might still be a good thing to do, because you reach a group not very interested in news (Editorial leader, national broadcaster). 
Further, many informants highlight DV's potential role in new forms of storytelling, for example, in the shape of stand-alone, exploratory visualizations, open for the user to create many different stories. Others point to the opportunity to innovate more traditional, linear forms:

The best way to do it, is to make what we call structured articles, which are linear in form, made for mobile platform and which give the readers good stops during the session. They have a visual element on top, not necessarily a dataviz, but something offering an angle. Then we guide the reader through the story, and also guide them into the dataset, telling them what it is good for. It makes a stop point in the linear reading, but not a place to stay for long (Leader of visual group, national broadsheet).

A related function is to offer an entrance to unseen stories. Many editorial leaders and leaders of visual groups emphasize the possibility of presenting stories, or aspects of stories, that could not be presented without the analysis and visualization of big data.

Techniques of crowd sourcing, used to harvest data directly from the audience through their responses to questions raised online, were also mentioned by several informants. These techniques have the double function of offering readers the role of active participants in media discourse and, at the same time, enabling them to monitor their own positions in the visualized landscape of public opinion.

\section{Platforms and tools}

When it comes to the practical realization of these discursive goals, infrastructural conditions affect production processes and outcomes. The study reveals that news designers are determined to follow their audience in the transition from desktop to mobile platforms. The 'mobile first' mantra was dominant in most newsrooms when it came to the design of data visualizations. This has strong implications for the preferred forms of visualizations - a turn towards simple visual forms with a low level of interactivity. One informant put it this way:

Generally, on a mobile, if you ask the readers to click on anything, they really need to know it's something important. Because most people won't click just to get something started (UX-designer, national broadsheet).

Also on the software side, there are developments that contribute to less semiotic complexity and more widespread application. First, the providers of standardized software for DV production, like the Canadian company Tableau and the Norwegian Highcharts, offer visualization software claiming a high level of flexibility and user friendliness. This offers opportunities for many non-experts to add simple data visualizations to their journalistic work. Second, almost all investigated newsrooms are in a process of developing an in-house 'toolbox' with a number of visualization tools for any journalist to use.

\section{Preferred types of data visualizations}

We have already stated that the study indicates a move towards simpler forms of data visualizations. Informants pointed to several reasons for this move: the 'mobile first' 
mantra, leading to forms that work well on a small screen; the development of easy-touse software, helping non-specialist journalists to make their own simple visualizations; and finally, reader statistics, which indicate that few readers make use of interactive options in data visualizations. However, the tendency towards simplicity is also based on professional arguments. Bar charts and line graphs are valued by many informants as the most effective forms of data visualizations. One informant said:

Even though bar charts may appear somewhat boring, they are often the most effective form of visualization (Developer, national broadsheet).

Another reported approach to this issue is to take the role of the educator, strengthening readers' visual literacy by presenting new forms of visualizations. One informant said:

If you offer a graph that works slightly differently from the usual ones, many readers won't have the patience to learn how to use it. At the same time, I think that it is important to make new things, and maybe not important that each and every user reads it (Developer, national broadsheet).

A third approach is to make visualizations more engaging by using sensory-stimulating visual elements in addition to, or replacing, simple geometrical forms. Some informants emphasize that iconic forms and pictograms can make a data visualization less abstract and more relatable. One informant said:

Often, it appears that a simple line graph or a bar graph is what you need to tell the story. But sometimes more iconic elements are useful. When we needed to illustrate the size of an Antonov, the world's biggest freight plane, we showed that it could carry 427,000 pizzas. Or the luggage to all inhabitants in a mediumsized Norwegian city. Not just the ten containers and two trucks that it actually did carry (Visual leader, national tabloid).

Some informants report that elements of animation sometimes are added. Animation is seen to be useful, both as an eye-catcher and as means for illustrating progress and change. One informant said:

We should not underestimate the value of a little playfulness. If you add some animation to a bar chart, you can show progression and change over time, in a manner that catches the reader's attention. She will more easily perceive that here is a big change, or here is no change at all. Larger changes will attract attention, simply because the animation lasts longer. So, animation can be much more than just eye-candy (Developer, national broadsheet).

Another dynamic form used in data visualization is zoomability. Zoomable maps are reported by many informants as a popular element in visualizations of data related to geographical places. In some cases, zoom techniques are also used to enable readers to explore other types of data visualizations in various levels of detail. One informant put it this way:

It is also fully possible to make a bar chart zoomable, to let the user explore data on a more detailed level - although we haven't done much of that yet (Developer, national broadsheet). 


\section{Relations to the reader}

An important aspect of all communication, verbal or visual, is the relation between the participants in the discourse (cf. Halliday 1978; Kress \& van Leeuwen 2006). When you know with whom you communicate, you can adapt your message accordingly. The findings in this study indicate that newsroom teams making DVs know rather little about their readers - for example, who they are and how they read DVs. None of the informants reported any kind of systematic user studies. On the contrary, the information they received from their readers through mail and social media is unsystematic and anecdotal. Many informants talked about reader statistics as their main source of reader information.

If you look at the stats, and look at what has been shared on social media, you get a good idea of what works. If readers like it, they probably have understood it (Data journalist, national broadcaster).

However, not all informants regard reader tracking as a reliable and relevant source of reader information. Several informants pointed to the fact that data visualizations can vary a great deal in forms and functions, so tracking statistics about a particular visualization does not necessarily produce broadly useful knowledge.

\section{Challenges and elements of tension}

Informants in the study reported on a number of challenges in the process of producing DVs relevant and suitable for journalism. Some are of a practical nature; others are a matter of principle, causing discussions both inside and amongst newsrooms. Problems reported concern, among other things, communication between disciplines, issues of time and skills, troublesome tools and unclear conventions.

On the whole, interviewees stated that cooperation in inter-disciplinary teams is a rewarding process. But at the same time, all groups of informants reported potential struggles. Talking about the collaboration between journalists and DV designers, one editorial leader said:

They sometimes have difficulties understanding each other. Understanding, in the sense that the journalist will have as much text as possible and the DV designer will have as little text as possible. That is how it goes. It is a kind of a struggle between two different disciplines. I will not call it a conflict, though, because each group respects the skills of the other (Editorial leader, national broadcaster).

Regarding skills and insights, some informants underlined that the biggest problem concerning DV is not the visualization itself but the analysis of big data sets. One editorial leader said:

We are simply not good enough when it comes to handling big sets of data, analyzing them and identifying the good stories in them. There, we have a huge learning curve ahead (Editorial leader, national broadsheet).

Also, on the software side, informants reported serious challenges. The fact that advanced DV production still is at an early stage in Scandinavian newsrooms is clearly 
reflected through in-house toolboxes, which are mostly projects under construction. One visual leader complained:

The toolbox that we use now is cumbersome, there are a lot of bugs. Only a handful of people actually manage to use it (Visual leader, national tabloid).

On the topic of genre development, several informants mentioned challenges concerning the lack of clear conventions. Unlike in writing, photography and layout, 'rules' concerning how DVs are designed and read in a journalistic context are still in the making. One informant illustrated the issue with these examples:

We have experienced that it may cause trouble if we use too many variables at the same time, for example, using a scatterplot with two axes together with bubbles of different sizes. What exactly does the size indicate? It is not always very clear. (...) Using color can also be problematic for several reasons. Using red and green, for instance. Those are colors that make people stop scrolling. But they are always associated with 'go' or 'don't go' - which is not necessarily what we want to say (Developer, national broadcaster).

Elements of tension revealed in the study have interesting implications concerning genre developments. Two issues emerge. The first relates to the question of whether it is a journalistic task to offer the reader an unguided exploration of a data set or not. The distinction between exploratory and illustrative data visualizations causes discussion inside newsrooms. Discussions concern both the question of resources, as exploratory visualizations generally are more resource intensive to produce, and questions related to the social role of journalism. How deeply should a news provider go into the role of being a general fact provider, if facts are not directly connected to a specific news event and not angled in a journalistic way? One informant said:

A lot of news media are now offering datasets that the readers can explore more or less freely. I think it's fun, because I work with data. But I don't believe it's journalism, offering no particular angle to the matter. I really don't (Digital editor, national broadcaster).

The second issue relates to whether ordinary journalists possess the skills needed to produce data visualizations. What kinds of skills are needed to produce a data visualization that meets the standards of professional journalistic discourse? Will a user-friendly tool and a one-day course provide a journalist with the necessary technological, graphical, statistical and communicational insights and skills? The informants in our study have different opinions on this issue. Some are skeptical about the idea of 'unleashing' data visualizations made by non-specialists. One put it this way:

There are so many mistakes you can make. You really need to be good at it, and I believe that only a minor group of regular journalists will be able to build up the necessary skills. This is not a toy that we are talking about. And after all, we are totally dependent on being trustworthy (Digital editor, national broadcaster). 


\section{Identifying trends and critical factors}

Reviewing the interview results, we can identify several trends and critical factors in the development of data visualization practices in Scandinavian newsrooms. They all influence practices and outputs and, thus, genre conventions. But they do not necessarily point in the same direction.

First, the construction of specialist groups connecting competencies within visual communication, digital interaction, data handling and coding with journalistic insights in news values and storytelling represents an assembly of strong innovative power. Since the early years of this decade, these groups have represented a new, creative resource in the newsrooms visited in the study, and they seem to be under rapid development when it comes to visual and communicational skills, work organization and internal impact on their respective newsrooms. All editorial leaders interviewed reported growing interest in data as a journalistic resource and many claimed that specialists within this field are prioritized when recruiting. Thus, the combination of human resources found in specialist groups can be assumed to function as a driver towards creative and innovative forms of data visualizations, typically found in special projects, serving various discursive intentions and carrying potential for expanding the repertoire of journalistic genres. These teams also represent a potential driver towards certain disruptions concerning organization and workflow in the newsroom.

Second, software development is a critical factor in the evolution of visualization practices. The building of locally adapted toolboxes and the growing use of commercial graphical shelf-ware offer opportunities for ordinary journalists to create simple data visualizations, such as bar charts, line graphs and maps, as add-ons to their news stories. This result is in line with findings from a quantitative study recently published by Florian Stalph (2017). At the same time, growing accessibility of user-friendly software indirectly supports the production of more complex DVs as well, because it frees time for expert teams to design more creative visualizations.

Third, the general move from big and medium-sized screens to small mobile screens as the preferred interface in the communication between news providers and their readers works as a driver towards simplicity and linearity when it comes to visual design. 'Mobile first' is a design mantra in all investigated newsrooms, although more explicitly expressed in some than others. Although some informants anticipate that creative designers will gradually become better at exploiting the smartphone's capabilities for advanced interaction, and thus create new solutions for complex and exploratory data visualizations also for this platform, most informants agree that 'mobile first' leads to simplicity and linearity. This trend thus appears to go hand in hand with one of the most traditional conventions of news genres, namely the basic structure of linear narrative. Following Appelgren (2017), this trend of strong linearity will enhance the level of 'journalistic paternalism', with the journalist taking the privileged role of storyteller, leaving little opportunity of choice-making to the reader.

Yet another critical factor for the development is user feedback generated from the registration of clicks and more advanced tracking of reader behaviour. This feedback is reported to indicate a generally low interest among readers in actively exploring data visualizations, especially among users of small mobile screens. Thus, it can be seen as a driver towards simpler forms of DV, demanding lower investments of time and mental effort from the reader. Many informants reported that user feedback is important for their assessment 
of their own visualization practices. But informants also reported that this automated feedback can be hard to interpret and even harder to use as a guide for future production. A more controlled form of user testing would give valuable insight into design issues, informants said, but none of the investigated newsrooms had routines for such testing.

These trends and critical factors indicate that the future development of data visualization practices in newsrooms will follow several trajectories at the same time. News audiences are likely to experience a growing presence of graphs, charts and maps in everyday news reporting. Parallel to this, expert teams will continue to develop innovative forms of DV in special projects and reports, published intermittently, and these may gradually shape conventions, making it easier for readers to interpret the multimodal codes in action. Comparing our findings to earlier research, our results indicate two things: that interest and investments in data visualization, even in more advanced forms, has been strengthened in Scandinavian newsrooms the last three to four years (cf. Appelgren \& Nygren 2014; Karlsen \& Stavelin 2014) and that the trend towards more but simpler DVs in everyday news combined with more creativity in occasional bigger projects, as reported by Loosen et al. (2017), Stalph (2017) and Young et al. (2017), can also be found in Scandinavian news rooms.

\section{Towards more 'fact-based' journalism?}

The trends and factors identified above serve as a contribution to understanding the bigger picture of change in journalistic genres and its relationship to other, more general trends. The development of digital tools and practices, competition from social media, the open data movement and the general datafication in society are factors external to newsroom practices, which significantly shape and influence them. These factors demand forms of adaption. The results from this study indicate that Scandinavian newsrooms indeed respond and adapt to this situation of change. Although the study reveals elements of tension and negotiation in the newsrooms when it comes to details in design and priorities, it clearly indicates that numeric data are used to an increasing extent and in a variety of forms in order to shape audiences' awareness of the world. In daily news stories, more attention is given to contextualizing news events with statistical information, and in occasional special reports, readers are invited to explore datasets on their own.

Returning to the issue of genre norms, we propose that these developments have implications for journalistic genres at large, their forms, contents and social functions. Arguably, they have potential to strengthen fact-based journalism in a situation where both facts and journalism are under attack from alternative values and actors in public discourse arenas. However, it might also lead to a news discourse where graphs and diagrams are used to give news stories an aura of objectivity, taking attention away from human choices and agencies that always shape textual outputs (cf. Lewis \& Westlund 2015; Wainer 2016; Hammond 2017). In either case, more studies are needed to monitor and further nuance our understanding of data visualization practices in newsrooms as well as their textual outputs and the norms and conventions they contribute to shape.

\section{Acknowledgements}

The research reported in this article was supported by The Norwegian Research Council (NFR) and The Norwegian Media Authorities (RAM). 


\section{Notes}

1. We use 'discourse' to refer to situated activities of communication and to the shaping of world views connected to these activities (cf. Fairclough 2003).

2. The article springs from the project Innovative Data Visualization and Visual-Numeric Literacy (see indvil.org). The project includes forthcoming articles covering both text analysis and user studies, related to journalistic data visualization.

3. Appelgren \& Nygren (2014) investigate data-driven journalistic practices from a similar perspective of genre change, but with less focus on visualization.

4. Other early insights in the field of DV in journalism are given by Flew at al. 2012; Weber \& Rall 2012; Appelgren \& Nygren 2014; Dick 2015; Fink \& Anderson 2015; Lewis \& Westlund 2015; de Maeyer et al. 2015.

5. In the interviews, the informants were also asked about issues concerning trust and objectivity. These topics are addressed in more detail in other articles emerging from the project.

\section{References}

Ahva, Laura; van Dalen, Arjen; Hovden, Jan Fredrik; Kolbeins, Guðbjörg Hildur; Löfgren-Nilsson, Monica; Skovsgaard, Morten \& Väliverronen, Jari (2017). A Welfare State of Mind? Nordic Journalists' Conception of their Role and Autonomy in International Context. Journalism Studies, 18(5): 595-613.

Appelgren, Ester \& Nygren, Gunnar (2014). Data Journalism in Sweden. Digital Journalism, 2(3): 394-405.

Appelgren, Ester (2017). An Illusion of Interactivity: The Paternalistic Side of Data Journalism. Journalism Practice. DOI: 10.1080/17512786.2017.1299032

Ausserhofer, Julian; Gutounig, Robert; Oppermann, Michael; Matiasek, Sara \& Goldgruber, Eva (2017). The Datafication of Data Journalism Scholarship: Focal Points, Methods, and Research Propositions for the Investigation of Data-Intensive Newswork. Journalism. DOI: 10.1177/1464884917700667

Bertin, Jaques (2011 [1967]). Semiology of Graphics: Diagrams, Networks, Maps. Redlands, CA: ESRI Press.

Boczkowski, Pablo (2004). The Processes of Adopting Multimedia and Interactivity in Three Online Newsrooms. Journal of Communication, 54(2): 197-213.

Borgo, Rita; Kehrer, Johannes; Chung, David; Maguire, Eamonn; Laramee, Robert; Hauser, Helwig; Ward, Matthew \& Chen, Min (2013). Glyph-Based Visualization: Foundations, Design Guidelines, Techniques and Applications. Eurographics State of the Art Reports. Available at http://www.ii.uib.no/vis/publications/publication/2013/pdfs/Borgo13GlyphBased.pdf [Accessed 16 January 2018].

Burmester, Michael; Mast, Marcus; Tille, Ralph \& Weber, Wibke (2010). How Users Perceive and Use Interactive Information Graphics: An Exploratory Study [Paper]. In Banissi, Ebad (ed.) Proceedings. 4th International Conference Information Visualization (IV 2010), London, 26-29 July, 2010.

Cairo, Alberto (2013). The Functional Art: An Introduction to Information Graphics and Visualization. Berkeley, CA: New Riders.

Cairo, Alberto (2016). The Truthful Art. Data, Charts, and Maps for Communication. Berkeley, CA: New Riders.

Couldry, Nick (2016). Foreword, in Kubitschko, Sebastian \& Kaun, Anne (eds.) Innovative Methods in Media and Communication Research. Basingstoke: Palgrave Macmillan.

de Maeyer, Juliette; Libert, Manon; Domingo, David; Heinderyckx, Francois \& Le Cam, Florence (2015). Waiting for Data Journalism. A Qualitative Assessment of the Anecdotal Take-Up of Data Journalism in French-Speaking Belgium. Digital Journalism, 3(3): 432-446.

Dick, Murray (2015). Just Fancy That: An Analysis of Infographic Propaganda in The Daily Express, 19561959. Journalism Studies, 16(2): 152-174.

Domingo, David (2008). Interactivity in the Daily Routines of Online Newsrooms: Dealing with an Uncomfortable Myth. Journal of Computer-Mediated Communication, 13(3): 680-704.

Engebretsen, Martin (2006). Shallow and Static or Deep and Dynamic? Studying the State of Online Journalism in Scandinavia. Nordicom Review, 27(1): 3-16.

Engebretsen, Martin (2008). Sakte utvikling mot en interaktiv nyhetsdiskurs [Moving Slowly towards an Interactive News Discourse]. Norsk Medietidsskrift, 15(6): 328-342.

Engebretsen, Martin (2017). Levende diagrammer og zoombare kart. Datavisualisering som nyskapende fortellerform i journalistikken [Vivid Diagrams and Zoomable Maps. Data Visualization as Innovative Form of Storytelling in Journalism]. Norsk Medietidsskrift, 24(02). DOI: 10.18261/issn.0805-9535-2017-02-02.

Engebretsen, Martin \& Weber, Wibke (2017). Graphic Modes, pp 277-295 in Cotter, Colleen \& Perrin, Daniel (eds.) Handbook of Language and Media. London: Routledge.

Fairclough, Norman (2003). Analysing Discourse: Textual Analysis for Social Research. New York, London: Routledge. 
Few, Stephen (2004). Show Me the Numbers: Designing Tables and Graphs to Enlighten. Oakland, CA: Analytics.

Fink, Katherine \& Anderson, Christopher (2015). Data Journalism in the United States: Beyond the "Usual Suspects". Journalism Studies, 16(4): 467-481.

Flew, Terry; Spurgeon, Christina; Daniel, Anne \& Swift, Adam (2012). The Promise of Computational Journalism. Journalism Practice, 6(2): 157-171.

Gynnild, Astrid (2013). Journalism Innovation Leads to Innovation Journalism: The Impact of Computational Exploration on Changing Mindsets. Journalism, 15(6): 713-730.

Halliday, Michael (1978). Language as a Social Semiotic. The Social Interpretation of Language and Meaning. London: Arnold.

Hammond, Philip (2017). From Computer-Assisted to Data-Driven: Journalism and Big Data. Journalism, 18(4): 408-424.

Hannaford, Liz (2015). Computational Journalism in the UK Newsroom: Hybrids or Specialists? Journalism Education, 4(1): 6-21.

Hullman, Jessica \& Diakopoulos, Nick (2011). Visualization Rhetoric: Framing Effects in Narrative Visualization. IEEE Transactions on Visualization and Computer Graphics, 17(12): 2231-2240.

Karlsen, Joakim \& Stavelin, Eirik (2014). Computational Journalism in Norwegian Newsrooms. Journalism Practice, 8(1): 34-48.

Kennedy, Helen \& Allen, William (2016). Data Visualization as an Emerging Tool for Online Research, in Fielding, Nigel; Lee, Raymond \& Blank, Grant (eds.) The Sage Handbook of Online Research Methods. London: Sage.

Kennedy, Helen; Hill, Rosemary; Aiello, Giorgia \& Allen, William (2016). The work that visualization conventions do. Information, Communication and Society, 19(6): 715-735.

Kirk, Andy (2016). Data Visualization. A Handbook for Data Driven Design. LA, London: SAGE.

Kosslyn, Stephen (2006). Graph Design for the Eye and Mind. New York: Oxford UP.

Kress, Gunther \& van Leeuwen, Theo (2006 [1996]). Reading Images. The Grammar of Visual Design. London: Routledge.

Krippendorf, Klaus (1980). Content Analysis. An Introduction to its Methodology. Beverly Hills: SAGE.

Lewis, Seth \& Westlund, Oscar (2015). Big Data and Journalism: Epistemology, Expertise, Economics, and Ethics. Digital Journalism, 3(3): 447-466.

Loosen, Wiebke; Reimer, Julius \& De Silva-Schmidt, Fenja (2017). Data-Driven Reporting: An On-going $(R)$ evolution? A Longitudinal Analysis of Projects Nominated for the Data Journalism Awards 2013-2016 (Arbeitspapiere des Hans Bredow Insituts, $n r$ 41). Hamburg: Hans-Bredow-Institut für Medienforschung, University of Hamburg.

Lüders, Marika; Prøitz, Lin \& Rasmussen, Terje (2010) Emerging Personal Media Genres. New Media \& Society, 12(6): 947-963.

Malamed, Connie (2009). Visual Language for Designers: Principles for Creating Graphics that People Understand. Beverly, MA: Rockport.

Mayer-Schoenberger, Viktor \& Cukier, Kenneth (2013). Big Data: A Revolution that will Transform how we Live, Work and Think. London: John Murray Publishing.

McMillan, Sally (2006). Exploring Models of Interactivity from Multiple Research Traditions: Users, Documents and Systems, pp. 205-229 in Lievrouw, Leah \& Livingstone, Sonia (eds.) The Handbook of New Media. London, Thousand Oaks, New Dehli: SAGE.

Meirelles, Isabel (2013). Design for Information: An Introduction to the Histories, Theories, and Best Practices behind Effective Information Visualizations. Beverly, MA: Rockport.

Miller, Carolyn (1984). Genre as Social Action. Quarterly Journal of Speech, 70(2).

Mollerup, Per (2015). Data Design. Visualising Quantities, Locations, Connections. London, New York: Bloomsbury.

Nussbaumer Knaflic, Cole (2015). Storytelling with Data. Hoboken, New Jersey: John Wiley \& Sons.

Rinsdorf, Lars \& Boers, Raol (2016). The need to Reflect: Data Journalism as an Aspect of Disrupted Practice in Digital Journalism and in Journalism Education. Proceedings of the Roundtable Conference of the International Association of Statistics Education (IASE), Berlin, July 2016.

Stalph, Florian (2017). Classifying Data Journalism. Journalism Practice. DOI: 10.1080/17512786.2017. 1386583.

van Dijck, Jose (2014). Datafication, Dataism and Dataveillance: Big Data between Scientific Paradigm and Ideology. Surveillance and Society, 12(2): 197-208.

Wainer, Howard (2016). Truth or Truthiness. NY: Cambridge University Press.

Weber, Wibke (2017). Interactive Information Graphics: A Framework for Classifying a Visual Genre, pp. 243-256 in Black, Alison; Luna, Paul; Lund, Ole \& Walker, Sue (eds.) Information Design: Research and Practice. Abingdon, New York: Routledge. 
Martin Engebretsen, Helen Kennedy \& Wibke Weber

Weber, Wibke \& Rall, Hannes (2012). Data Visualization in Online Journalism and Its Implications for the Production Process, pp. 349-356 in Banissi, Ebad (ed.) Information Visualization. Proceedings 16th International Conference on Information Visualization (IV 2012), IEEE Computer Society.

Yau, Nathan (2011). Visualize This: The Flowing Data Guide to Design, Visualization, and Statistics. Indianapolis, IN: Wiley Pub.

Young, Mary Lynn \& Fulda, Johanna (2017). What Makes for Great Data Journalism? A Content Analysis of Data Journalism Awards Finalists 2012-2015. Journalism Practice. DOI: 10.1080/17512786.2016.1270171.

MARTIN ENGEBREtSEn, Professor, Department of Nordic and Media Studies, University of Agder, martin.engebretsen@uia.no

HELEN KENNEDY, Professor, Department of Sociological Studies, University of Sheffield, h.kennedy@sheffield.ac.uk

WIBKE WEBER, Professor, Institute of Applied Media Studies, Zürich University of Applied Sciences, wibke.weber@zhaw.ch 